University of Nebraska - Lincoln

DigitalCommons@University of Nebraska - Lincoln

Educational Psychology Papers and

Publications

Educational Psychology, Department of

1990

Rationality as a Goal of Education

David Moshman

University of Nebraska-Lincoln, dmoshman1@unl.edu

Follow this and additional works at: https://digitalcommons.unl.edu/edpsychpapers

Part of the Educational Psychology Commons

Moshman, David, "Rationality as a Goal of Education" (1990). Educational Psychology Papers and Publications. 89.

https://digitalcommons.unl.edu/edpsychpapers/89

This Article is brought to you for free and open access by the Educational Psychology, Department of at DigitalCommons@University of Nebraska - Lincoln. It has been accepted for inclusion in Educational Psychology Papers and Publications by an authorized administrator of DigitalCommons@University of Nebraska - Lincoln. 
Published in Educational Psychology Review 2:4 (1990), pp. 335-364.

Copyright (c) 1990 Plenum Publishing Corporation. Used by permission.

\title{
Rationality as a Goal of Education
}

\author{
David Moshman \\ Department of Educational Psychology \\ University of Nebraska-Lincoln, \\ Lincoln, Nebraska 68588-0641, USA
}

\begin{abstract}
Those who believe education should involve more than learning facts often stress either (a) development or (b) thinking skills. A focus on development as a goal of education typically entails a conception of knowledge as organismic, holistic, and internally generated. In contrast, thinking skills programs commonly assume a mechanistic, reductionist perspective in which good thinking consists of some finite number of directly teachable skills. A conception of rationality as a goal of education is proposed that incorporates the complementary strengths and avoids the limitations of the developmental and thinking skills approaches. Rationality is defined as the self-reflective, intentional, and appropriate coordination and use of genuine reasons in generating and justifying beliefs and behavior. Philosophically, rationality is a justifiable goal of education, not only because it is a means to worthwhile ends but because it is an important end in itself and because it can be promoted via non-indoctrinative means. A psychological account of progressive rationality is provided that postulates continuing multiple interactions of (a) domain-specific developmental stages, (b) the learning of specific thinking skills, and (c) content-specific knowledge. Suggestions are made for fostering rationality at various educational levels. Finally, it is argued that the proposed conception of rationality as a goal of education complements and clarifies a variety of other educational goals.
\end{abstract}

Keywords: critical thinking, development, education, rationality, thinking skills

\section{Introduction}

Everyone agrees that education should involve more than the rote learning of facts. There is no consensus, however, about just what the ma- 
jor goals of education should be. There is even less agreement about how to formulate, articulate, and pursue these goals (Cole, 1990).

In the next two sections of this paper I will present and analyze two important current approaches to education. The first of these proposes that education should aim, at least in part, at fostering students' development. The other focuses on the inculcation of thinking skills. Although each of these approaches has given rise to a number of specific programs, I will not describe these programs or summarize evaluations of them. Rather, my aim is to provide a general overview of the two global approaches, with a focus on the strengths and limitations of each and the complementary nature of these strengths and limitations. I will then propose an alternative view of rationality as a goal of education that, I will argue, (a) preserves most of the strengths and avoids many of the weaknesses of the developmental and thinking skills approaches, (b) has a clear philosophical justification and psychological basis, and (c) convincingly addresses a variety of difficult educational issues.

\section{Development as a Goal of Education}

Most teachers would probably agree that they are interested in their students' development and that development is a proper and important goal of education. Some see development as the primary aim of education (Kohlberg and Mayer, 1972), and some educational programs are explicitly developmental (Black, 1989). For present purposes, I will define a developmental program as one that sees development as a relatively global, long-term, internally generated process and that attempts to facilitate that process. This would include, for example, Piagetian programs aimed at facilitating cognitive development (e.g., Schwebel and Raph, 1973) and Kohlbergian moral education programs (e.g., Reimer et al., 1983).

Just to be clear about the focus here, it may be helpful to rule out some other sorts of educational approaches or programs that often are labeled developmental. First, most educational approaches stress the importance of adapting instruction to the learner's current level of understanding. If the learner's current level is construed in developmental terms (e.g., the learner is concrete operational), such an approach is using knowledge of development. Such an approach would not be developmental in the present sense, however, unless it is intended to further development (e.g., to formal operations). Second, some educational programs stress attention not just to learning and cognition but to the whole individual, including social, emotional, and personality factors. Such an approach is not developmental, however, unless it is intended to foster long-term development in these other realms. Finally, the term "developmental" is often used to 
refer to remedial programs. But although it is possible to take a developmental approach to remediation of deficiencies, remediation is not per se developmental.

\section{General Characteristics of a Developmental Approach}

Developmental approaches to education share at least two major characteristics: (a) an organismic conception of knowledge and thinking, and (b) a view of change as primarily due to or directed by endogenous factors. I will discuss each of these characteristics in turn.

\section{Organismic Worldview}

Developmentalists generally see knowledge and thinking in biological terms - that is, as living, growing structures. These structures have important systemic properties and cannot be reduced to the specific facts and skills included within them. Thus, for example, any addition of one number to another can be reversed through the corresponding subtraction (e.g., $4+2=6 ; 6-2=4$ ). This is not a property of any particular number in isolation, nor of the operation of addition alone, nor of the operation of subtraction alone. Rather it is a property of the overall structure of elementary arithmetic. The developmental educator would insist that such understanding is fundamental and that it cannot meaningfully be taught as a specific fact. Rather, it must grow out of an increasingly structured understanding of mathematics. The focus, then, is on relatively general, long-term changes in cognition.

\section{Endogenous Basis for Change}

Moreover, the developmentalist would argue that meaningful knowledge and generalizable skills are produced via internal processes rather than being taken in from the environment. The many versions of this view can be classified roughly into two general categories: (a) nativist or maturational, and (b) constructivist. Nativist views stress the hereditary basis for knowledge. Although an extended process of maturation in an appropriate environmental context may be necessary, such maturation is strongly guided by a preexisting genetic program (e.g., Chomsky, 1980; Keil, 1981). Constructivist views are similar in their emphasis on internal guidance of development but deemphasize or deny genetic determination and stress instead the active construction of knowledge by the individual (e.g., Kohlberg, 1984; Piaget, 1983, 1985). The environment may facilitate or hinder such construction but the ba- 
sis for and guidance of change is primarily internal. Most developmental educators of the past several decades take a constructivist rather than a nativist or maturational view.

\section{Analysis and Critique of Developmental Approaches}

Developmental approaches to education have several important strengths that may account for their substantial influence. One is the recognition of structural considerations in knowledge and change. It is now widely agreed that knowledge and ability are not a collection of facts and skills but rather reflect complex, integrated, and changing structures. Moreover, there is increasing recognition that structural changes cannot be understood without attention to a variety of internal self-regulatory forces (Klahr, 1984). Finally, a number of specific developmental theories have been proposed that can serve as a basis for developmental programs in education (e.g., Campbell and Bickhard, 1986; Case, 1985; Fischer, 1980; Kohlberg, 1984; Piaget, 1985).

One issue for any developmental approach to education is specifying the stages through which children are intended to progress or the nature of what they are supposed to achieve. The multiplicity of developmental theories provides an opportunity for the educator to choose a theory that suits his or her conception of development and/or goals for education. But this also creates a problem with respect to justifying such choices. Piaget's theory, for example, has been extensively criticized on the grounds that it is vague in its characterizations of the various stages and transition processes, that to the extent that its claims can be ascertained they are substantially inconsistent with available evidence, and that even to the extent that the stages are clear and empirically adequate they focus too narrowly on logic and fail to provide a comprehensive picture of development (Campbell and Bickhard, 1986; Case, 1985; Flavell, 1985; Gelman and Baillargeon, 1983; Sternberg, 1984). The proliferation of neo-Piagetian and post-Piagetian theories over the past two decades attests to the fact that there exists no definitive general model of human development that can serve as a firm basis for education.

Moreover, even given a clear, empirically supported, and comprehensive developmental theory, it would not immediately follow that educators are justified in promoting progress toward the higher stages of that theory. It is logically possible that human beings naturally change in the direction of inappropriate processes of reasoning, irrationally fixed ideas, or an immoral focus on self-interest, and that education should be aimed at hindering or stopping this natural process. What is natural is not necessarily good; to justify an educational approach requires more than showing that it facilitates certain natural tendencies. 
Finally, although the developmental perspective is a useful corrective to the empiricist assumption that students are blank slates on which educators write, it may be an overcorrective. The environment may play a far greater role in development than maturational or constructivist theories generally acknowledge (Elbers, in press; Flavell, 1985; Rogoff, 1990). Certainly educators need to be seriously attentive to the potential of the educational environment to generate (not merely facilitate) important change. It may be possible to overcome some of these problems by focusing on rationality. To the extent that later stages in a developmental sequence are demonstrably more rational, they may justifiably be seen as higher - not just later-stages, and there is a stronger basis for promoting them. It may even be useful to specifically formulate stages of rationality that are purposely narrower than general stages of development, an approach I will pursue later in this article. Another possibility, however, is not to worry about stages or development at all but rather to focus on the direct transmission of specific thinking skills, an approach to which we now turn.

\section{Thinking Skills as a Goal of Education}

A wide variety of educational approaches and programs are aimed at producing good thinkers through activities aimed at the improvement of thinking. The programs and approaches addressed in this section are those that define thinking in terms of specific skills and attempt to foster good thinking not by facilitating some underlying developmental process but rather through relatively direct inculcation (Adams, 1989; Baron, 1985; Baron and Sternberg, 1987; Beyer, 1990; Blair and Johnson, 1987; Chance, 1986; de Bono, 1983; Hudgins and Edelman, 1988; Miller, 1986; Nisbett et al., 1987; Sternberg and Martin, 1988). Those associated with this perspective tend to use terms such as "critical thinking," "higher order thinking skills," or "informal logic."

\section{General Characteristics of Thinking Skills Approaches}

Thinking skills programs and approaches are difficult to characterize in that they are highly diverse and at best connected by some ill-defined "family resemblances." Nevertheless, for present purposes, I will ignore the diversity and focus on the similarities. Most programs and approaches within this category differ systematically from the developmental perspective discussed earlier in that they appear to be committed to (a) a mechanistic conception of thinking and (b) a view of change as primarily due to and directed by exogenous factors. 
Mechanistic Worldview

Most (although not all) thinking skills advocates appear to see the mind in mechanical terms, as a very sophisticated computer. Thinking is construed as the processing of information. Good thinking, it is assumed, can be understood reductionistically by dissecting it into the specific processes or thinking skills that comprise it.

\section{Exogenous Basis for Change}

Just as one can program a computer to process information well, advocates of thinking skills believe one can program a mind to think well. By specifying the specific thinking skills that comprise good thinking, one can then directly teach each skill to whatever level of proficiency is deemed desirable. The focus, in other words, is not on indirectly facilitating the emergence of new cognitive structures that will enable better thinking (as in a developmental approach), but rather on the direct inculcation of specific thinking skills. It is assumed that good thinking can be reduced to a finite set of specifiable skills and that such skills can be directly taught. As Adams (1989, p. 27) puts it,

The fundamental assumption motivating all curricula on thinking is that there exists a certain set of skills or processes that are common to thinking in general, regardless of person, domain, or purpose. The common goal of the curricula is to teach those processes ....

\section{Critique of the Thinking Skills Approach}

Proponents of a thinking skills approach to education have provided some admirably specific and useful lists of fundamental thinking skills (e.g., Ennis, 1987). Moreover, many have been unusually clear and thoughtful in proposing means for teaching such skills and for assessing what students have learned. Although "critical thinking" has become something of a buzzword in educational circles, there can be no doubt that the thinking skills movement, far from being a passing fad, is a permanent and important part of the field of education. The limitations of most current work on thinking skills are closely related to these strengths. First, although published lists of major thinking skills cover a number of obviously important skills, they are generally based on formal logic, informal logic, and/or some intuitive taxonomy of thinking abilities rather than on any general, empirically supported theory of reasoning. Thus, the relative importance of the various skills listed is open to question, as is the comprehensiveness of the entire list. 
Moreover, the reduction of thinking to any finite set of cognitive skills may reflect an overly narrow view (Wassermann, 1989). Even among those closely associated with the critical thinking movement, there is concern about basing thinking skills education on a restrictive conception of good thinking. Matthew Lipman, for example, discussing his "Philosophy for Children" program, notes that "[i]t's of little value to possess individual cognitive skills if one lacks judgment as to when such skills should be applied. The aim of philosophy is to develop thinkers, and that cannot be done by merely teaching skills" (interview by Brandt, 1988, p. 37; see also Beyer, 1990; Lipman, 1988; Paul, 1987; Siegel, 1988; Sternberg, 1987; Sternberg and Martin, 1988).

Finally, the emphasis on direct teaching leads to a lack of attention to endogenous factors, such as relatively spontaneous maturation or active mental construction, that may be critical to the progress of reasoning. Even if direct teaching is demonstrably effective, it does not follow that only exogenous factors are worthy of consideration in educating students.

It appears, then, that the strengths and limitations of the developmental and thinking skills approaches may be complementary. Perhaps an integration of the two perspectives would generate a view that usefully related specific thinking skills to more general mental structures and that could address the interaction of internal and external sources of change. On the other hand, given the major differences in basic assumptions underlying the two approaches, it should not be assumed that such an integration will be easy, if it is feasible at all (Moshman, 1982; Reese and Overton, 1970).

It is not the purpose of this article to provide a general synthesis of these two perspectives. It does appear to me, however, that it may be possible to propose an approach that incorporates the strengths of both views and avoids some of the limitations of each. A key to this limited integration is a concept narrower than development but broader than critical thinking that in some respects gets at the essence of each. I propose that we consider a major goal of education to be rationality.

\section{The Philosophy of Rationality}

Consideration of rationality as a goal of education raises a variety of philosophical, psychological, and educational questions. Philosophically, we must clarify what we mean by rationality and justify promoting it via education. Psychologically, we must understand actual human rationality and its development. Finally, with respect to education, we must develop a plan to promote rationality in schools and consider its relation to other educational goals. I will address each of these matters in turn in the remaining three sections of this article. 


\section{The Nature of Rationality}

I have elsewhere defined rationality as the self-reflective, intentional, and appropriate coordination and use of genuine reasons in generating and justifying beliefs and behavior (Moshman, 1989; Moshman and Hoover, 1989). In this section I will explicate that definition with emphasis on its relevance to education.

Central to the definition is the idea that rationality involves an appeal to reasons (Rescher, 1988; Siegel, 1988; Strike, 1982a). To the extent that ideas or actions are arbitrary or caused by external forces, there is a lack of rationality. One is rational to the extent that one chooses what to believe or do and has reasons for those choices. Moreover, one's various reasons are coordinated with each other in a quest for some degree of consistency and coherence. Thus, an educational program has failed to produce rationality to the extent that students have no reasons for their beliefs and behavior or have reasons that are mutually inconsistent.

Furthermore, rationality includes some degree of self-reflection and intentionality. A student who mechanically uses certain problem-solving or inference procedures that have been drilled in is no more rational than a computer that acts in accord with its program. Rational thinkers purposely decide to think, know they are thinking, know why they are thinking, and can even reflect on the adequacy and effectiveness of their own thought processes. Rationality, in other words, is inherently metacognitive.

In addition, it is important that one's reasons are genuine in the sense that they objectively justify what they are intended to support and that the coordination and use of the reasons is normatively appropriate. Knowing, of course, is always subjective in that it takes place from, and reflects, a point of view. There is no denying the uncertainties that this creates. It does not follow, however, that all reasons and all uses of reasons are equally good. Learning to identify and value good reasons, and to use them well, is critical to becoming more rational.

Finally, education does not promote rationality if it merely teaches students how to provide post hoc rationalizations for what they would have believed or done anyway. Rationality means using reasons as a basis for generating new actions and ideas, as well as justifying previous ones.

It should be apparent, then, that by rationality I mean something narrower than development but broader than thinking skills. A focus on rationality can help us keep in mind (a) why and in what respects development is relevant to education and (b) why we should concern ourselves with students' thinking. If rationality is a justifiable goal of education, then we should promote students' development at least to the extent that 
development moves toward greater rationality and we should promote thinking skills at least to the extent that such skills further rationality. (I leave aside until the last section the question of what other goals, if any, education ought to have.)

\section{Philosophical Justification of Rationality as a Goal of Education}

I will argue in this section that rationality should be a major goal of education because (a) it serves as a means to positive ends, (b) it is an important end in itself, and (c) its promotion is consistent with a nonindoctrinative approach to education.

Rationality as a Means to Positive Ends

It should be clear that rationality as I have defined it is relevant to all aspects of life. Whatever one's personal goals, one is more likely to attain them if one has reasons for what one believes and does and regularly coordinates and reflects on those reasons than if one acts arbitrarily, reflexively, or on the basis of unexamined and/or mutually inconsistent reasons. Moreover, community welfare and economic development are likely to be furthered if members of the community behave rationally in this same sense. Furthermore, democratic self-government operates best if citizens are capable of making rational political decisions. Promotion of rationality, then, serves a variety of personal, community, and governmental purposes and is thus an important goal of education.

Rationality as an End in Itself

The rationale for promoting rationality goes deeper than its usefulness, however. Even if rationality could not be shown to serve any of the above purposes, it would still have a claim as an important focus of education. A central assumption in our way of life is that we are all autonomous beings worthy of respect. If education is intended at least in part to transmit our values to our children and thus assure some degree of continuity from generation to generation, then education should affirm our commitment to personal autonomy and dignity.

But autonomy without rationality is meaningless. Unless one can formulate and act on reasons of one's own, one cannot genuinely make a choice and there is at best an illusion of autonomy. Only rational beings are capable of autonomy and dignity in the usual senses of these words. Rationality is thus not simply a means to promote autonomy and dignity but an essential component of both (Siegel, 1988; Strike, 1982a). Thus, we should educate children in a way that promotes rationality not only be- 
cause this serves as a means to other ends but because such education is an affirmation of who we are and what we value (Rescher, 1988; Weinstein, 1988).

The concept of political liberty likewise assumes rational citizens. To the extent that insect behavior is caused, rather than based on self-conscious reasons, no political arrangement could turn an anthill into a democracy. A democracy can only be composed of individuals capable of making autonomous political choices. Promoting the rationality of future voters not only may lead to better choices and thus better government (a means argument already made above), but affirms our commitment to political liberty and a democratic system. Once again, rationality is not only a means to other ends but a central component of our way of life and thus an end in itself.

\section{Rationality and Indoctrination}

Finally, to the extent that rationality permits students to voluntarily and spontaneously criticize ideas and form their own conceptions, it serves to liberate them intellectually. Education inevitably inculcates various ideas and values (Arons, 1983; Moshman, 1989; Strike, 1982b). An educational system that limits itself to inculcation, however, is morally suspect in that it may treat students solely as a means to further the ends of those who select the ideas and values to inculcate. To the extent that rationality is one of its goals, however, an educational system enables students to question for themselves and set their own intellectual course. The system thus avoids indoctrination in that whatever ideas and values are inculcated become starting points for rational analysis rather than rigid limits on reasoning (Siegel, 1988).

But isn't the promotion of rationality itself a sort of indoctrination? If by rationality we meant an unquestioning commitment to certain fixed patterns of reasoning, this would indeed be a serious objection. But rationality as defined above is inherently self-reflective. Rational persons subject their own reasons and reasoning, even their commitment to rationality itself, to critical scrutiny. The promotion of rationality, then, is not an indoctrinative implantation of a fixed ideology. On the contrary, it is a liberating influence (Siegel, 1988). In the case of American public schools, indoctrination is a constitutional, as well as a moral, problem (West Virginia v. Barnette, 1943). Clearly, it would severely undercut First Amendment freedoms of belief and expression, as well as the more general constitutional ideal of government by the will of the people, if government were to mold the beliefs of each generation via government-run schools (Arons, 1983; Moshman, 1989; van Geel, 1983, 1986). To the extent that public schools promote rationality and thus avoid indoctrination, they promote freedoms of belief and expression, 
and democratic political choice, rather than undermining these constitutional ideals.

\section{The Psychology of Rationality}

If one accepts the argument that promotion of rationality should be a major goal of education, the next question is how this is best achieved. To address that question requires analysis of the psychology of rationality. Rationality, however, though much discussed in the psychological literature (see Baron, 1985; Cohen, 1981), has not been systematically studied by psychologists (Moshman, 1990b). Although there is extensive research on human reasoning, most psychological work on rationality has been limited to determining whether the reasoning of children and adults on various tasks is consistent with logical norms. But as discussed earlier with respect to definition, rationality is not simply a matter of conformity to logical norms. I have therefore been preoccupied in recent years with developing a more meaningful psychological theory of rationality and its development (e.g., Moshman, 1990b; Moshman and Hoover, 1989; Moshman and Lukin, 1989). I present below a fragment of that theory and adapt it to the educational issues of concern in this article.

\section{The Development of Rationality}

\section{Deductive Rationality}

A key aspect of rationality is deductive reasoning. To the extent that one makes proper deductive inferences from well-justified premises, there are strong reasons for believing in and acting upon one's conclusions. To the extent that one's deductions are inappropriate, one's conclusions are not rationally justified. Available evidence does not support the view that proper deductive reasoning suddenly appears at any particular point in development. In fact, there is substantial evidence that preschool children routinely reach appropriate conclusions from various combinations of premises (Braine, 1990; Braine and Rumain, 1983; Hawkins et al., 1984; Markovits et al., 1989; Thayer \& Collyer, 1978) and that even adults typically fail to reach appropriate conclusions for a variety of complex logical problems (Evans, 1982, 1983; Wason and Johnson-Laird, 1972).

The strongest evidence for developmental stages of deductive rationality, in my view, is seen with respect to the criterion that genuine rationality is self-reflective. Even when preschool children reach correct conclusions they appear to have no sense of their conclusions as conclusions. That is, because they are unaware of having engaged in a process of reasoning, they do not grasp the critical distinction between a deduced conclusion 
and the premises from which it was deduced. Their focus is on the content of the premises and conclusions, not on the relation between them.

Beginning about age 5 or 6 , however, children appear to be increasingly intentional and self-reflective in reaching and evaluating conclusions. This shows up, for example, in the ability to recognize the logical necessity of deductive conclusions (Fabricius et al., 1987; Pieraut-Le Bonniec, 1980; Somerville et al., 1979), to recognize and deal with undecidability in cases where the premises are insufficient to reach a conclusion (Braine and Rumain, 1983; Scholnick and Wing, 1988), and to grasp the possibility of gaining knowledge through inference as opposed to direct observation or communication (Sodian and Wimmer, 1987).

Although elementary-age children thus appear to be at a higher stage of rationality in the domain of deductive logic than preschool children, their reflective awareness of their own logic is still limited. Specifically, although their ability to distinguish logically necessary inferences from inferences that are merely plausible, probable, or conventional reveals an implicit awareness of the logical form of arguments, they do not appear to reflect explicitly on the nature and role of logical form. Beginning about age 11 or 12, there is evidence of movement toward a third, qualitatively distinct stage at which reflective awareness of logical form is sufficiently explicit to distinguish the internal validity of an entire argument (whether the conclusion follows necessarily from the premises) from the external truth of specific propositions within an argument (whether a specific premise or conclusion is empirically true). Thus, for example, adolescents but not younger children are likely to grasp the validity of an argument such as "If elephants are either animals or plants, and elephants are not animals, then elephants are plants" (Moshman and Franks, 1986). Stage 3 deductive rationality is also revealed in the ability to grasp the nature of tautologies and logical contradictions (Cummins, 1978; Osherson and Markman, 1975; Russell and Haworth, 1987) and to distinguish logic from other epistemological domains (Komatsu and Galotti, 1986).

Although most adolescents appear capable of Stage 3 understanding about the nature of logic, application of this competence to actual problems is imperfect and continues to develop at least through adolescence ( $\mathrm{O}^{\prime}$ Brien, 1987; Overton, 1990; Overton et al., 1987). Further reflection on the nature of logic may yield, in some highly educated adults, an increasingly explicit (Stage 4) metalogical understanding of the nature and interrelations of logical system and natural languages (Moshman, 1990a; Politzer, 1986).

It appears, then, that evidence supports the reality of a series of qualitatively distinct stages in the development of deductive reasoning. In construing this as a matter of emerging rationality, what is critical is not the reaching of correct conclusions but the increasing ability to intentionally and reflectively deploy and coordinate one's deductive inference schemata (Moshman, 1990a). 


\section{Inductive Rationality}

A similar picture can be provided for inductive reasoning. Even preschool children routinely make a variety of appropriate inductive inferences. Very young children, however, fail to reflect on their own subjectivity and thus have great difficulty distinguishing their own perceptions and conclusions from reality itself (Taylor and Hort, 1990). Over the course of development, children become increasingly able to distinguish their beliefs from reality, to understand the possibility of different people having different perspectives, interpretations, and beliefs, and to recognize the need to justify beliefs (Astington et al., 1988; Clinchy and Mansfield, 1986; Flavell, 1985, 1986; Flavell et al., 1986, 1990; Flavell et al., 1987; Gopnik and Astington, 1988; Pillow, 1988). This transition appears to begin about age 4 . By age 6 or 7 children typically have a fairly clear understanding of the various ways in which appearances can be deceiving and of the need to verify one's conceptions of reality by accumulating evidence, Elementary school-age children are still limited, however, in their level of understanding about the nature and justification of beliefs. Beginning about age 11, adolescents show an increasingly explicit understanding of the distinction between theories and data and the relation between these (Kuhn, 1989; Kuhn et al., 1988), and an increasing inclination to intentionally test theories by directly seeking potentially falsifying data (Moshman, 1979; O'Brien, 1987; O'Brien et al., 1986; O'Brien and Overton, 1980, 1982; Overton et al., 1987; Ward and Overton, 1990). Application of Stage 3 inductive rationality remains inconsistent even in adolescents and adults (Kuhn, 1989; Kuhn et al., 1988; Overton, 1990). Nevertheless, it appears that at least some individuals move beyond Stage 3 to a Stage 4 level of explicit metatheoretical awareness involving highly sophisticated conceptions about reality, knowledge, truth, and justification (Broughton, 1978; Kitchener et al., 1989).

\section{Moral Rationality}

Finally, one can provide a similar picture for the emergence of moral rationality. Central to Kohlberg's (1984) theory of moral development is a focus not on the content of the individual's moral views but on the structure of his or her reasoning. The Stage 1 child understands and uses simple moral rules (e.g., "don't hit"). Stage 2 children (typically elementary school-age) have a sufficient grasp of others' perspectives and the logic of social reciprocity to comprehend the reason for moral rules. The Stage 3 individual (typically an adolescent) understands the basis for reciprocity and consideration of other perspectives in the nature and value of human relationships. Individuals who reach Stage 4 (typically in late adolescence or early adulthood) reflect on relationships themselves from the perspec- 
tive of broader social, political, and religious systems. And individuals who achieve Stage 5 (rare even in adults) explicitly analyze social, political, and/or religious systems with respect to general principles of justice. The overall progression may be considered to move in the direction of greater rationality in that each stage involves a conscious reflection on the assumptions of the previous stage and thus an appeal to and coordination of a deeper level of reasons.

\section{Reflective Abstraction}

What accounts for the progression from stage to stage? Each of the three domains of development just discussed involves a very different set of stages. I make no claim for cross-domain consistency. There is, however, an important consistency in the nature of the relationship between successive stages in each sequence. Each stage may be seen as a conscious reflection on the previous stage that renders the basic assumptions of that earlier stage explicit and thus available for a reconstruction that will better coordinate them. This is essentially the process that Piaget has labeled "reflective abstraction" (see Campbell and Bickhard, 1986). Reflective abstraction may be construed as a very powerful form of metacognition that doesn't just illuminate, monitor, or direct the execution of cognitive processes but actively reconstructs cognition at a higher level of abstraction or, to shift the metaphor, a deeper level of understanding. Reflective abstraction may be postulated as central to the development of rationality in that it ensures that successive stages will not just be different from each other but that each will be a self-reflective reconstruction of the previous one that makes implicit assumptions explicit and thus allows a better awareness and coordination of reasons (Moshman and Lukin, 1989).

\section{Learning to Be Rational: A Thinking Skills Critique}

Proponents of the teaching of thinking skills would probably level a variety of criticisms at the above picture. I will focus on two that I think are particularly apt. First, the stages postulated in each domain are vague about the actual reasoning processes individuals use and the actual coordination of those processes. Accounts of developmental stages generally do not address the real-time processing of information at the level of detail one commonly sees in information-processing approaches (Sternberg, 1984). This does not mean developmental stage accounts are incorrect, but it does mean they are incomplete.

Moreover, the focus on development as an endogenous construction that moves in a predictable direction suggests that the learning of specific thinking skills is either not possible or not important to the development 
of rationality. But there is in fact substantial evidence that, under appropriate pedagogical circumstances, students can learn important thinking skills, maintain those skills over time, and apply them to new content (Lehman et al., 1988; Nisbett et al., 1987). Such learning may play a major role in the development of rationality.

Both of the above criticisms of a purely stage-developmental approach to rationality are reasonable. But rejection of the developmental account in favor of an account of rationality as the learning of thinking skills would, in my view, be an unjustified overreaction that would raise equally serious problems of its own. For one thing, without denying that meaningful thinking skills can be learned, the fact remains that it is difficult to teach such skills in such a way that they endure and transfer to new content (Sternberg and Martin, 1988). A general theory of rationality must not only explain how meaningful teaching of thinking skills is possible but why it is difficult. Part of that explanation, it seems to me, would be that learning thinking skills is not a simple matter of imitating "observed" patterns of reasoning but rather involves active assimilation of instructed skills to current reasoning and understanding, a process in which, as developmentalists have long insisted, the learner plays an active, constructive role.

Moreover, given the earlier definition of rationality as the self-reflective, intentional, and appropriate coordination and use of genuine reasons, the learning of thinking processes can only further rationality if (a) the processes learned are normatively justifiable processes that provide genuine reasons for accepting the conclusions to which they lead, (b) the student understands the nature and justification of these processes, and (c) the student has voluntary control over the application of the processes. Presumably, we would not refer to a thinking process as a skill unless it was indeed normatively justifiable. (Committing the fallacy of affirming the consequent, for example, is a cognitive process but we would not label it a "skill.") Developers and teachers of thinking skills curricula obviously do not include just any process; they identify mental processes that constitute good thinking. Thus, criterion $a$ is generally met in that the use of thinking skills by students does provide reason to believe in the conclusions they reach or accept.

But if students are merely learning to apply whatever processes their teachers inculcate, and especially if such applications are automatic and routine, then the only rationality is in the mind of the educator, who has reflected on the nature and appropriateness of the processes to be inculcated and has decided, on the basis of such reflection, to inculcate them. The student, far from being a rational agent, simply thinks as she or he has been taught to think. To the extent that criteria $b$ and $c$ are not met, the result of a thinking skills curriculum is a carefully programmed set of thinking processes, which, according to the earlier definition, cannot 
qualify as genuine rationality. This does not mean thinking skills should not be taught, but suggests that for such instruction to promote rationality it must encourage active reflection on the part of the student about the nature and use of the skills in question.

\section{Development and Thinking Skills: A Partial Integration}

It therefore appears that a comprehensive account of rationality must address both (1) the internal reflective processes of the mind and the resulting developmental stages and (2) the ongoing learning of a variety of skills and strategies from the environment. Moreover, these should be seen as opposite poles of a continuum rather than as independent and sharply distinct cognitive phenomena (Elbers, in press; Rogoff, 1990). Internal logical structures must be linked to the world via the use of specific skills and strategies, and learned skills and strategies must be coordinated with one's more general level of understanding via active assimilation. Although the learning of skills beyond one's current level of development is generally difficult and somewhat superficial, such skills nevertheless may not only be learned but may serve as the cutting edge of development. Correspondingly, although a variety of skills can be directly learned, such skills only become fully meaningful through a developmental process of active reflection and reconstruction. Students thus become progressively more rational through a continuing interaction of endogenous forces, leading to increasingly integrated and abstract cognitive structures, and exogenous forces, leading to an increasingly sophisticated set of thinking skills (Moshman, 1990a).

Consider, for example, the strategy of testing hypotheses by seeking potentially falsifying data. A strictly developmental approach would note that this (Stage 3) strategy emerges over the course of adolescence and would argue that it cannot be directly taught. The developmentalist would suggest, however, that construction of the falsification strategy can be facilitated by providing consolidated Stage 2 inductive reasoners with extensive opportunity to test hypotheses, thus increasing the likelihood that they will notice and reflect on the inadequacies of their Stage 2 understanding, and thereby construct the more sophisticated Stage 3 approach. Thus, the developmentalist would speak not of teaching and learning but of the facilitation of development.

A thinking skills proponent, on the other hand, would argue for directly demonstrating how to seek falsifying data and would suggest that if this is properly done, with due attention to prerequisite skills, motivation, transfer, and so forth, all students at virtually any age should adopt this strategy. The focus, then, is on teaching and learning. Development, if one must use the term at all, is (from this perspective) simply the process of learning and generalizing a variety of skills over a long period of time. 
The present integration suggests that development and learning can be distinguished but that neither dominates the other. The Stage 2 student who learns to test hypotheses by seeking falsifying data will find this strategy in conflict with his or her natural tendency to affirm hypotheses by seeking confirming data. The resulting disequilibrium will lead to reflection on the nature and relations of theories, data, verification, and falsification, ultimately resulting in a reconstructed (Stage 3) understanding. The learning of the falsification strategy may be seen as playing a causal role in initiating this process and even to some extent in directing it, but it is the individual's endogenous reflection that renders falsification part of a general inductive rationality rather than a learned procedure. Development, then, is in some sense directed by learning (as thinking skills proponents would have it) but (as developmentalists would insist) is not simply an accumulation of what one has learned.

\section{The Role of Content Knowledge}

I have so far presented the developmental and thinking skills views as being at the opposite ends of the theoretical spectrum and have attempted to integrate them. But despite their very real differences, these two approaches in fact share an important and controversial assumption. Both assume general modes of reasoning that are applied across content areas.

Prior to the 20th century, the mind was widely conceived as a sort of undifferentiated muscle that could be strengthened through rigorous exercise. Thus, "formal training" in Latin and other rigorous subjects was considered fundamental to a general strengthening of the mind (Lehman et al., 1988). Though early psychological research showed a lack of transfer from one content area to another (see Nisbett et al., 1987), modern versions of the generality thesis remained dominant until well into the 1970s. Many psychologists saw formal logic as central to good reasoning and there has been a steady stream of research on logical reasoning for most of the present century (Rips, 1990). In the psychometric tradition, factor analytic studies of intelligence concluded that, underlying the multiple forms of intelligence, was a general intellectual factor, which was labeled simply $g$ (see Perkins and Salomon, 1(89). Within developmental psychology, the work of Piaget (e.g., 1983) led to a strong focus on general stages of cognitive development. Finally, early information-processing theorists focused on general problem-solving (e.g., Miller et al., 1960; Newell and Simon, 1972). It was, as Perkins and Salomon (1989, p. 17) put it, "the golden age of general heuristics."

But beginning in the 1970s and increasingly in the early 1980s psychologists questioned the importance of formal logic and of general abilities, 
structures, and heuristics. Research suggested that good thinking was primarily a matter of expertise in the content area of concern (Chase and Simon, 1973; Chi, 1978; Keil, 1984; see Perkins and Salomon, 1989). Concepts such as broad, universal developmental stages and general thinking skills were increasingly questioned (see Weinstein, 1988).

Generality conceptions have never died, however, and in the last few years there are indications that the pendulum may be swinging back. It is frequently argued that there are indeed broad cognitive skills or competencies though these may be less consistently applied (Kuhn, 1989; Overton, 1990) or different in nature (Lehman et al., 1988; Light et al., 1989; Nisbett et al., 1987) than was earlier believed. There may even be an emerging consensus that general and content-specific factors are both important and that psychologists and educators should focus not on which set of factors is primary' but rather on how the two sets interact (Alexander and Judy, 1988; Linn et al., 1989; Overton, 1990; Perkins and Salomon, 1989; Schauble, 1990; Siegler, 1989; Sternberg, 1989). Moreover, the very distinction between "general" and "content-specific" is seriously compromised by pervasive ambiguities about just what constitutes a "domain" of content (Ceci, 1989; Ennis, 1989).

Even if content is not the predominant factor in reasoning, however, it is clearly very' important. What are the implications of this with respect to rationality? Reasoning within and on the basis of a given body of knowledge can only be considered rational, by the earlier definition, to the extent that (a) the body of knowledge is well-justified, (b) the reasoner has a reflective understanding of that justification, and (c) application of the knowledge is intentional. Consider, for example, a student working on physics problems. To the extent the student applies modern principles of physics, she or he is indeed using a body of well-justified knowledge, thus satisfying criterion $a$. But rationality requires that, in addition, the student understand the justifiability of the knowledge being applied. Otherwise, as discussed earlier, there is simply a programmed application of processes that others have decided to teach. Thus, it is important the student understand that modern knowledge of physics has been produced through centuries of scientific research and that science is a rational social tradition that has systematic processes for reflective critique and revisions of belief through the intentional collection and use of data. For full rationality to be granted, then, the student must have a reflective understanding of the content-knowledge used that goes far beyond the specific domain of content to more general forms of reasoning (such as the strategy of testing hypotheses by seeking falsifying data). The student must understand how modern physics has been generated by the social tradition we call science and must understand how that social tradition operates in accord with general rational 
principles. Moreover, rational application of content-knowledge would be based on purposeful and appropriate judgments concerning its applicability. To the extent that content-knowledge rigidifies into a fixed set of concepts and procedures over which the thinker has no metacognitive control, it yields what Sternberg (1989, p. 118) labels "the dark side of expertise."

Reasoning and Content-Knowledge: A Further Integration

We may thus conclude that thinking generally involves an interaction of both general reasoning and content-knowledge. Moreover, it is not enough for a student to mindlessly apply some combination of general and content-specific algorithms. For thinking to be designated as rational the thinker must understand the nature and justification of both the thinking processes and the body of content-knowledge and must intentionally apply and integrate these in a manner that reflects such understanding.

\section{Rationality as a Goal of Education}

What are the educational implications of the philosophical and psychological analyses of rationality? It is not my intention to provide a specific program or curriculum for the promotion of rationality. Existing developmental and thinking skills programs may in fact already be doing a good job of this without having been formulated with rationality explicitly in mind. My aim in this section is to make some very general recommendations concerning the promotion of rationality at various educational levels, to consider the place of rationality in the curriculum, and to consider the relation of rationality to other educational goals.

\section{Recommendations for Various Educational Levels}

Preschool

The psychological evidence indicates that rationality is developing in very young children and suggests that it can be promoted even in the preschool years. Preschool children are becoming aware of their own reasoning and subjectivity. Rationality may be promoted at this age by encouraging children to state their beliefs, to describe their own behavior, and to provide reasons for both. The focus should be less on logical or moral correctness than on fostering clear articulation and a commitment to justification. 


\section{Elementary School}

Once children show a clear awareness of their reasoning and subjectivity, typically by the early elementary school years, the focus can shift to systematic strategies for generating conclusions, verifying beliefs, and interacting with others. For example, this might include discussion of what can be concluded from various premises, what counts as evidence in favor of certain scientific theories, and why one should be fair to others.

\section{Secondary School}

As students move into adolescence, they are increasingly capable of more explicit reflection on the form of logical arguments, the relation of hypotheses and data, and the nature and role of human relationships. They are ready for increasingly abstract consideration of what it means for an argument to be valid, the logic of testing hypotheses by seeking falsifying data, and the nature and purpose of morality .

\section{Higher Education}

Finally, college and graduate education can continue the level of discussion begun at the secondary level and encourage students to pursue such matters with increasing autonomy and move toward increasingly explicit attention to metalogical, metaethical, and epistemological considerations.

\section{Placement in Curriculum}

Any approach to education that suggests goals beyond the teaching of content must consider where in the curriculum those goals are to be achieved. To put the matter in dichotomous terms, should activities aimed at achieving these goals be infused throughout the curriculum (e.g., included in existing content- specific courses) or should the new activities be integrated and accomplished as a package (e.g., in a specific new course on thinking or rationality)? Arguments for the package approach generally stress the need to assure and monitor implementation and the possibility of achieving transfer by specifically training for it. Arguments for infusion generally stress the content-specificity of cognition and/or the difficulties of transfer.

As we have seen, rationality involves a complex interaction of general and content-specific considerations. One can thus make a case for ei- 
ther approach. The ideal, it seems to me, is a combination of both. Infusion has the important advantage of helping students see the rational considerations in various content areas; a course in rationality may help students see what these rational considerations have in common across content and thus develop a more general sense of and commitment to rationality per se. The two approaches, then, are not conflicting but complementary (Sternberg, 1987). There is reason to believe that either can be of some use and that neither alone is optimal.

\section{Relation to Societal Goals of Education}

The various goals of education can be divided, roughly, into two categories: those aimed most directly at the furtherance of society and those aimed most directly at the benefit of the student. The first category would thus include the passing on from generation to generation of society's knowledge, values, morality, and traditions. The second category would include goals such as emotional development or the enhancement of creativity. Although the distinction between these two categories is far from sharp-social continuity is presumably good for individuals, and individual development is presumably good for society - I will consider societal goals in the present section and child-oriented goals in the next section.

\section{Inculcation of Content-Knowledge}

Is an educated individual (a) one who has substantial knowledge in important content areas (e.g., history, literature, science) or (b) one who is well-developed, a good thinker, or something of that sort? Traditionalists who see education as the passing on of our culture's accumulated knowledge are likely to stress the teaching of content. Those who see education as preparing students to live in and adapt to an unforeseeable future are likely to stress the promotion of optimal development, good thinking, or something of that sort.

To the extent that we take rationality to be a major goal of education, we see the educated person as one who self-reflectively coordinates and uses genuine reasons. An accumulated mass of isolated historical, scientific, and/or other facts is unlikely to promote rationality. But contentknowledge need not be such an accumulated mass of facts (Cole, 1990). On the contrary, it may consist of structured knowledge and contentspecific modes of reasoning that society has produced via rational processes known to and understood by the student (Perkins, 1986). To the extent that this is the case, content-knowledge may play a critical role in 
helping the student reflectively generate and justify beliefs and behavior. General modes of reasoning and understanding may play an important role in rationality to the extent that they supplement, and lead students to reflect critically on, such content-knowledge, but they cannot fully replace such knowledge. Thus, with respect to rationality, content-knowledge and general reasoning should be seen as complementing each other rather than as incompatible goals for education.

Inculcation of Values and Morality

Should education address issues of values and morality, and, if so, how? Discussions of this often assume that such issues can only be addressed by either (a) directly inculcating unshakable commitments to certain values and moral rules, or (b) helping students clarify whatever values and moral conceptions they happen to hold. The first approach smacks of indoctrination and is certainly inconsistent with rationality in that it involves a fixation of beliefs that are intended to be impervious to further experience and reasoning. The second approach smacks of relativism and is equally inconsistent with rationality in its implication that all values and moral conceptions are equally acceptable, that it is wrong to question people's beliefs in this area, and that such beliefs cannot be or need not be justified (Strike, 1982a). Given these two unattractive alternatives, one is strongly tempted to argue that schools should simply avoid dealing with values and morality.

But for an educational system interested in the promotion of rationality, such avoidance itself suggests moral relativism by implying that values and morality lie outside the domain of rationality. An approach more consistent with rationality is to reject the above dichotomy. One can, after all, propose and model a variety of values and moral behaviors without compelling an irrational commitment to these. Moreover, one can encourage students to coordinate and reflect on their own values and moral conceptions in a way that suggests rational analysis leading to genuine change is desirable but without compelling any particular changes. By focusing students attention on moral reasoning and encouraging coordination of values and detection of internal inconsistencies, schools may help students see that there can be reasons for moral beliefs and behavior and reasons to change or maintain one's values. In other words, it is possible and important for schools to highlight and promote moral rationality. The domain of values and morality may be especially sensitive (Moshman, 1989), but it is not in principle any different from other domains that schools routinely encompass. Its exclusion from the curriculum is inconsistent with a broad view of rationality as a goal of education. 


\section{Inculcation of Social Traditions}

At the heart of the questions of content-knowledge, values, and morality is an even broader issue of whether the main focus of education should be to pass on social traditions or to criticize them. It might seem at first that a commitment to rationality, reasoning, critical thinking, personal development, or the like would be contrary to a view of education as passing on existing social traditions. But the view that rationality and tradition are inherently at odds unnecessarily assumes that a student must either (a) mindlessly accept all the traditions of his or her society or (b) reflexively reject all such traditions (see Hyland, 1986). There is no reason to posit such a choice. What rationality requires is a reflective critique of social traditions. Teaching the existing traditions in considerable depth is obviously necessary for such a critique and must thus be part of any education oriented toward rationality. The outcome of such a reflective critique of a deeply understood tradition would depend on the student's assessment of the reasons for the tradition. On the basis of such analysis a student might indeed utterly reject a given tradition. It is equally possible, however, that the student might not only accept the tradition but emerge from the analysis more firmly committed to it than she or he would otherwise have been.

Our social traditions and institutions have evolved over many years and play critical and incompletely understood roles in our society (Campbell, 1975). We should not assume out of hand that social evolution is purely arbitrary or repressively political. There may be good reasons for some traditions and for the form some social institutions take (Hyland, 1986). The present approach assumes that our various social traditions and institutions should be well understood and reflectively considered and that acceptance or rejection of each should be based on such consideration by students.

There is, moreover, a deeper reason why rationality should not be seen as inherently in opposition to social tradition. Rationality itself is, by any account, one of our oldest and most important traditions (Rescher, 1988; Strike, 1982a; Weinstein, 1988). Underlying our various moral, legal, political, and social traditions and institutions is a longstanding conception of each individual as a rational agent, reflectively deciding what to think and do and accepting the responsibility for those decisions and actions. Far from undermining tradition, then, education for rationality affirms and supports one of our oldest and most basic traditions. 


\section{Relation to Child-Oriented Goals of Education}

Enhancing Emotional Development

On the basis of a sharp distinction between cognition and emotion it might be argued that education should focus on cognition (knowledge and/or thinking) and leave the emotional realm (including, perhaps, matters of social and/or personality development) to the home and/or other institutions. In fact, it might even be suggested that education for rationality should involve teaching students to keep their emotions in check so they can perceive and reason objectively and thus understand and act on rational rather than emotional grounds.

But such an analysis is not justified by the present conception of rationality. Strong emotions can, of course, interfere with rational analysis and response, but absence of emotion may mean absence of the motivation to be rational. The definition of rationality provided earlier does not construe it in any way as the absence of emotion, nor does it imply that strong emotion is inherently inconsistent with rationality (Moshman and Hoover, 1989). On the contrary, the rational being is one committed to the use of reasons and, in human beings at least, such commitment is likely to have a strong emotional dimension. However sophisticated one's cognitive potential, it is unlikely that one will intentionally seek, coordinate, and evaluate reasons unless one approaches a matter with a "critical attitude" (Siegel, 1988, pp. 39-42). Such an attitude is at least as much a matter of emotion as a matter of cognition (Beyer, 1990; Paul, 1987). The rational person is tolerant of uncertainty, feels negatively about cognitive constraints and biases, and feels positively about free intellectual inquiry. In fact, a case can be made that for the truly rational person such epistemic values as truth, consistency, and objectivity become highly reinforcing ends in themselves, allowing us to propose the fundamental role of what philosophers (e.g., Paul, 1987; Siegel, 1988, p. 40) label "the rational passions."

\section{Promoting Creativity}

Finally, what about creativity? Does the constant and intentional seeking of reasons preclude the "letting go" necessary for genuine creativity? Is there thus an inconsistency, or at least a troubling degree of interference between rationality and creativity as goals of education?

Once again, a misleading dichotomy is itself the problem (Bailin, 1987). Creativity may indeed involve a degree of loose brainstorming or a rejection of the commonplace in which rationality plays little or no role. But 
a person who simply spews forth a constant stream of outlandish ideas and reflexively disagrees with what everyone else believes is not thereby creative. She or he is simply bizarre and disagreeable. Genuine creativity involves not only the generation of new possibilities, perhaps on the basis of unorthodox assumptions, but the systematic evaluation of possibilities and the reflective identification and analysis of implicit assumptions. Thus, rationality is not only consistent with creativity but plays a central role in it.

Moreover, rationality as defined here is not simply a learned set of thinking skills but involves increasingly sophisticated levels of reflection constructed by the active mind. In other words, rationality is itself creatively constructed (Moshman and Lukin, 1989). Rationality is thus both a product and a source of creativity, and its promotion is fully consistent with the educational promotion of creativity.

\section{Conclusion}

I have argued that rationality should be a major (though not necessarily the only) goal of education. Such an approach is consistent with a commitment to development as a goal of education provided one focuses on aspects of development (such as the emergence of rationality) that can be justified as educational goals independent of their empirical status as typical developmental phenomena. Similarly, the rationality approach is consistent with the teaching of thinking skills provided one values thinking skills for their promotion of rationality and teaches them in a way consistent with this goal. Rationality can be philosophically justified as an educational goal and is well enough understood psychologically to suggest how such a goal may be furthered. Moreover, the present conception of rationality as a goal of education clarifies and complements a variety of other educational aims.

Nevertheless, anyone who quickly and easily endorses rationality as an educational goal has not understood its implications. To foster rationality is not simply to promote development toward a particular stage or to inculcate a specific set of ideas, skills, perspectives, or propensities. Genuine rationality is unpredictable, open-ended, and potentially subversive. To educate for rationality is to facilitate processes of reflection and reconstruction from which nothing - not even rationality itself - is secure. 


\section{Acknowledgments}

This article was solicited by, and is dedicated to, John Glover, the late editor of Educational Psychology Review, who was a living example that rationality need not be cold, predictable, or boring. An earlier version was presented at the June 1989 meeting of the Jean Piaget Society in Philadelphia. I am grateful to Kathy Cauley who served as discussant at that presentation; to Karl Hostetler, who served as discussant at a more recent local presentation; to Richard Kitchener and Harvey Siegel, for helpful comments on the manuscript; and to two anonymous reviewers for their exceptionally detailed and thoughtful reviews.

\section{References}

Adams, M. J. (1989). Thinking skills curricula: Their promise and progress. Educ. Psychol. 24:25-77.

Alexander, P. A., and Judy, J. E. (1988). The interaction of domain-specific and strategic knowledge in academic performance. Rev. Educ. Res. 58: 375-404.

Arons, S. (1983). Compelling Belief: The Culture of American Schooling, McGraw-Hill, New York.

Astington, J. W., Harris, P. L., and Olson, D. (eds.) (1988). Developing Theories of Mind, Cambridge University Press, New York.

Bailin, S. (1987). Critical and creative thinking. Informal Logic 9: 23-30.

Baron, J. (1985). Rationality and Intelligence, Cambridge University Press, New York.

Baron, J. B., and Sternberg, R. J. (eds.) (1987). Teaching Thinking Skills: Theory and Practice, Freeman, New York.

Beyer, B. K. (1990). What philosophy offers to the teaching of thinking. Educ. Leadership 46: 55-60.

Black, A. (ed.) (1989). Developmental teacher education. The Genetic Epistemologist 17.

Blair, J. A., and Johnson, R. R. (1987). The current state of informal logic. Informal Logic 9: 147-151.

Braine, M. D. S. (1990). The "natural logic" approach to reasoning. In Overton, W. F. (ed.). Reasoning. Necessity, and Logic: Developmental Perspectives, Erlbaum, Hillsdale, New Jersey, pp. 133-157.

Braine, M. D. S., and Rumain, B. (1983). Logical reasoning. In Flavell, J. H., and Markman, E. M. (eds.), Mussen, P. H. (series ed.). Handbook of Child Psychology: Vol. 3. Cognitive Development, Wiley, New York, pp. 263-340.

Brandt, R. (1988). On philosophy in the curriculum: A conversation with Matthew Upman. Educ. Leadership 46: 34-37.

Broughton, J. M. (1978). Development of concepts of self, mind, reality, and knowledge. In Damon, W. (ed.). Social Cognition, New Directions for Child Development, No. 1, Jossey-Bass, San Francisco, pp. 75-100.

Campbell, D. T. (1975). On the conflicts between biological and social evolution and between psychology and moral tradition. Am. Psychol. 30: 1103-1126.

Campbell, R. L., and Bickhard, M. H. (1986). Knowing Levels and Developmental Stages, Karger, Basel.

Case, R. (1985). Intellectual development: Birth to Adulthood, Academic Press, Orlando, Florida. 
Ceci, S. J. (1989). On domain specificity ... More or less general and specific constraints on cognitive development. Merrill-Palmer Quart. 35: 131-142.

Chance, P. (1986). Thinking in the Classroom: A Survey of Programs, Teachers College Press, New York.

Chase, W. G., and Simon, H. A. (1973). The mind's eye in chess. In Chase, W. G. (ed.), Visual Information Processing, Academic Press, New York, pp. 215-281.

Chi, M. T. H. (1978). Knowledge structures and memory development. In Siegler, R. S. (ed.), Children's Thinking: What Develops? Erlbaum, Hillsdale, NJ, pp. 73-96.

Chomsky, N. (1980). On cognitive structures and their development: A reply to Piaget. In Piattelli-Palmarini, M. (ed.). Language and Learning: The Debate Between Jean Piaget and Noam Chomsky, Harvard University Press, Cambridge, MA, pp. 35-52.

Clinchy, B. M., and Mansfield, A. F. (1986). The child's discovery of the role of the knower in the known. Paper presented at the meeting of the Jean Piaget Society, Philadelphia.

Cohen, L. J. (1981). Can human irrationality be experimentally demonstrated? Behav. Brain Sci. 4: 317-370.

Cole, N. S. (1990). Conceptions of educational achievement. Educ. Res. 19: 2-7.

Cummins, J. (1978). Language and children's ability to evaluate contradictions and tautologies: A critique of Osherson and Walkman's findings. Child Dev. 49: 895-897.

de Bono, E. (1983). The direct teaching of thinking as a skill. Phi Delta Kappan 64: 703-708.

Elbers, E. (in press). The development of competence and its social context. Educ. Psychol. Rev.

Ennis, R. H. (1987). A taxonomy of critical thinking dispositions and abilities. In Baron, J. B., and Sternberg, R. J. (eds.). Teaching Thinking Skills: Theory and Practice, Freeman, New York. pp. 9-26.

Ennis, R. H. (1989). Critical thinking and subject specificity: Clarification and needed research. Educ. Res. 18: 4-10.

Evans, J. St. B. T. (1982). The Psychology of Deductive Reasoning, Routledge and Kegan Paul, London.

Evans, J. St. B. T. (ed.) (1983). Thinking and Reasoning: Psychological Approaches, Routledge and Kegan Paul, London.

Fabricius, W. V., Sophian, C., and Wellman, H. M. (1987). Young children's sensitivity to logical necessity in their inferential search behavior. Child Dev. 58: 409-423.

Fischer, K. W. (1980). A theory of cognitive development: The control and construction of hierarchies of skills. Psychol. Rev. 87: 477-531.

Flavell, J. H. (1985). Cognitive Development, 2nd ed., Prentice-Hall, Englewood Cliffs, NJ.

Flavell, J. H. (1986). The development of children's knowledge about the appearancereality distinction. Am Psychol. 41: 418-425.

Flavell, J. H, Green, F. L., and Flavell, E. R. (1986). Development of knowledge about the appearance-reality distinction. Monographs of the Society for Research in Child Development 51 (1, Serial No. 212).

Flavell, J. H, Green, F. L., and Flavell, E. R. (1990). Developmental changes in young children's knowledge about the mind. Cognitive Dev. 5: 1-27.

Flavell, J. H, Green, F. L., Wahl, K. E, and Flavell, E. R. (1987). The effects of question clarification and memory aids on young children's performance on appearance-reality tasks. Cognitive Dev. 2: 127-144.

Gelman, R., and Baillargeon, R. (1983). A review of some Piagetian concepts. In Flavell, J. H., and Markman, E M. (eds.), Mussen, P. H (series ed.). Handbook of Child Psychology: Vol. 3. Cognitive Development, Wiley, New York, pp. 167-230. 
Gopnik, A., and Astington, J. W. (1988). Children's understanding of representational change and its relation to the understanding of false belief and the appearance-reality distinction. Child Dev. 59: 26-37.

Hawkins, J., Pea, R. D., Glick, J., and Scribner, S. (1984). “Merds that laugh don't like mushrooms": Evidence for deductive reasoning by preschoolers. Dev. Psychol. 20: 584-594.

Hudgins, B. B., and Edelman, S. (1988). Children's self-directed critical thinking. J. Educ. Res. 81: 262-273.

Hyland, J. T. (1986). Instruction, rationality, and learning to be moral. J. Moral Educ. 15: 127-138.

Keil, F. C. (1981). Constraints on knowledge and cognitive development. Psychol. Rev. 88: 197-227.

Keil, F. C. (1984). Mechanisms of cognitive development and the structure of knowledge. In Sternberg, R. J. (ed.). Mechanisms of Cognitive Development, Freeman, New York, pp. 81-99.

Kitchener, K. S., King, P. M., Wood, P. K., and Davison, M. L. (1989). Sequentiality and consistency in the development of reflective judgment: A six-year longitudinal study. J. Applied Dev. Psychol. 10: 73-95.

Klahr, D. (1984). Transition processes in quantitative development. In Sternberg, R. J. (ed.), Mechanisms of Cognitive Development, Freeman, New York, pp. 101-139.

Kohlberg, L. (1984). Essays on Moral Development: Vol. II. The Psychology of Moral Development, Harper \& Row, New York.

Kohlberg, L., and Mayer, R. (1972). Development as the aim of education. Harv. Educ. Rev. 42: 449-496.

Komatsu, L. K., and Galotti, K. M. (1986). Children's reasoning about social, physical, and logical regularities: A look at two worlds. Child Dev. 57: 413-420.

Kuhn, D. (1989). Children and adults as intuitive scientists. Psychol. Rev. 96: 674-689.

Kuhn, D., Amsel, E, and O'Loughlin, M. (1988). The Development of Scientific Thinking Skills, Academic Press, New York.

Lehman, D. R., Lempert, R. O., and Nisbett, R. E. (1988). The effects of graduate training on reasoning: Formal discipline and thinking about everyday-life events. Am Psychol. 43: 431-442.

Light, P., Blaye, A., Gilly, M., and Girotto, V. (1989). Pragmatic schemas and logical reasoning in 6- to 8-year-old children. Cognitive Dev. 4: 49-64.

Linn, M. C., Clement, C., Pulos, S., and Sullivan, P. (1989). Scientific reasoning during adolescence: The influence of instruction in science knowledge and reasoning strategies. J. Res. Sci. Teaching 26: 171-187.

Lipman, M. (1988). Critical thinking - What can it be? Educ. Leadership 46: 38-43.

Markovits, H., Schleifer, M., and Fortier, L. (1989). Development of elementary deductive reasoning in young children. Dev. Psychol. 25: 787-793.

Miller, G. A., Galanter, E., and Pribram, K. H. (1960). Plans and the Structure of Behavior, Holt, Rinehart \& Winston, New York.

Miller, R. B. (1986). Toward an empirical definition of thinking skills. Informal Logic 8: 113-124.

Moshman, D. (1979). Development of formal hypothesis-testing ability. Dev. Psychol. 15: 104-112.

Moshman, D. (1982). Exogenous, endogenous, and dialectical constructivism. Dev. Rev. 2: 371-384.

Moshman, D. (1989). Children, Education, and the First Amendment: A Psycholegal Analysis, University of Nebraska Press, Lincoln. 
Moshman, D. (1990a). The development of metalogical understanding. In Overton, W. F. (ed.), Reasoning, Necessity, and Logic: Developmental Perspectives, Erlbaum, Hillsdale, NJ, pp. 205-225.

Moshman, D. (1990b). Reason, reasons, and reasoning. Paper presented at the meeting of the Jean Piaget Society, Philadelphia.

Moshman, D., and Franks, B. A. (1986). Development of the concept of inferential validity. Child Dev. 57: 153-165.

Moshman, D., and Hoover, L. M. (1989). Rationality as a goal of psychotherapy. J. Cognitive Psychother. 3: 31-51.

Moshman, D., and Lukin, L. E. (1989). The creative construction of rationality: A paradox? In Glover, J. A., Ronning, R. R., and Reynolds, C. R. (eds.), Handbook of Creativity, Plenum, New York, pp. 183-198.

Newell, A., and Simon, H. A. (1972). Human Problem Solving, Prentice-Hall, Englewood Cliffs, NJ.

Nisbett, R. E., Fong, G. T., Lehman, D. R., and Cheng, P. W. (1987). Teaching reasoning. Science 238: 625-631.

O'Brien, D. P. (1987). The development of conditional reasoning: An iffy proposition. In Reese, H. W. (ed.), Advances in Child Development and Behavior, Vol. 20, Academic Press, Orlando, FL, pp. 61-90.

O'Brien, D. P., Costa, G., and Overton, W. F. (1986). Evaluations of causal and conditional hypotheses. Quart. J. Exp. Psychol. 38A: 493-512.

O'Brien, D. P., and Overton, W. F. (1980). Conditional reasoning following contradictory evidence: A developmental analysis. J. Exp. Child Psychol. 30: 44-60.

O'Brien, D. P., and Overton, W. F. (1982). Conditional reasoning and the competenceperformance issue: A developmental analysis of a training task. J. Exp. Child Psychol. 34: 274-290.

Osherson, D. N., and Markman, E. (1975). Language and the ability to evaluate contradictions and tautologies. Cognition 3: 213-226.

Overton, W. F. (1990). Competence and procedures: Constraints on the development of logical reasoning. In Overton, W. F. (ed.), Reasoning, Necessity, and Logic: Developmental Perspectives, Erlbaum, Hillsdale, NJ, pp. 1-32.

Overton, W. F., Ward, S. L., Noveck, I. A., Black, J., and O'Brien, D. P. (1987). Form and content in the development of deductive reasoning. Dev. Psychol. 23: 22-30.

Paul, R. W. (1987). Dialogical thinking: Critical thought essential to the acquisition of rational knowledge and passions. In Baron, J. B., and Sternberg, R. J. (eds.). Teaching Thinking Skills: Theory and Practice, Freeman, New York, pp. 127-148.

Perkins, D. N. (1986). Knowledge as Design, Erlbaum, Hillsdale, NJ.

Perkins, D. N., and Salomon, G. (1989). Are cognitive skills context-bound? Educ. Res. 18: $16-25$.

Piaget, J. (1983). Piaget's theory. In Kessen, W. (ed.), Mussen, P. H. (series ed.). Handbook of Child Psychology: Vol. 1. History, Theory, and Methods, Wiley, New York, pp. 103-128.

Piaget, J. (1985). The Equilibration of Cognitive Structures: The Central Problem of Intellectual Development, University of Chicago Press, Chicago.

Pieraut-Le Bonniec, G. (1980). The Development of Modal Reasoning: Genesis of Necessity and Possibility Notions, Academic Press, New York.

Pillow, B. H. (1988). The development of children's beliefs about the mental world. Merrill-Palmer Quart. 34: 1-32.

Politzer, G. (1986). Laws of language use and formal logic. J. Psycholinguistic Res. 15: 47-92. 
Reese, H. W., and Overton, W. F. (1970). Models of development and theories of development. In Goulet, L. R. and Baltes, P. B. (eds.), Life-Span Developmental Psychology: Research and Theory, Academic Press, New York, pp. 115-145.

Reimer, J., Paolitto, D. P., and Hersh, R. H. (1983). Promoting Moral Growth: From Piaget to Kohlberg, 2nd ed., Longman, New York.

Rescher, N. (1988). Rationality. Oxford University Press, New York.

Rips, L. J. (1990). Reasoning. Ann. Rev. Psychol. 41: 321-353.

Rogoff, B. (1990). Apprenticeship in Thinking: Cognitive Development in Social Context, Oxford University Press, New York.

Russell, J., and Haworth, H. M. (1987). Perceiving the logical status of sentences. Cognition 27: 73-96.

Schauble, L. (1990). Belief revision in children: Role of prior knowledge and strategies for generating evidence. J. Exp. Child Psychol. 49: 31-57.

Scholnick, E. K., and Wing, C. S. (1988). Knowing when you don't know: Developmental and situational constraints. Dev. Psychol. 24: 190-196.

Schwebel, M., and Raph, J. (1973). Piaget in the Classroom, Basic Books, New York.

Siegel, H. (1988). Educating Reason: Rationality, Critical Thinking, and Education, Routledge, London.

Siegler, R. S. (1989). How domain-general and domain-specific knowledge interact to produce strategy choices. Merrill-Palmer Quart. 35: 1-26.

Sodian, B., and Wimmer, H. (1987). Children's understanding of inference as a source of knowledge. Child Dev. 58: 424-433.

Somerville, S. C., Hadkinson, B. A., and Greenberg, C. (1979). Two levels of inferential behavior in young children. Child Dev. 50: 119-131.

Sternberg, R. J. (ed.) (1984). Mechanisms of Cognitive Development, Freeman, New York.

Sternberg, R. J. (1987). Questions and answers about the nature and teaching of thinking skills. In Baron, J. B. and Sternberg, R. J. (eds.), Teaching Thinking Skills: Theory and Practice, Freeman, New York, pp. 251-259.

Sternberg, R. J. (1989). Domain-generality versus domain-specificity: The life and impending death of a false dichotomy. Merrill-Palmer Quart. 35: 115-130.

Sternberg, R. J., and Martin, M. (1988). When teaching thinking does not work, what goes wrong? Teachers College Record 89: 555-578.

Strike, K. A. (1982a). Educational Policy and the Just Society, University of Illinois Press, Urbana.

Strike, K. A. (1982b). Liberty and Learning, St. Martin's Press, New York.

Taylor, M., and Hort, B. (1990). Can children be trained in making the distinction between appearance and reality? Cognitive Dev. 5: 89-99.

Thayer, E. S., and Collyer, C. E. (1978). The development of transitive inference. Psychol. Bull. 85: 1327-1343.

van Geel, T. (1983). The search for constitutional limits on governmental authority to inculcate youth. Texas Law Rev. 62: 197-297.

van Geel, T. (1986). The Constitution and the child's right to freedom from political indoctrination. In Moshman, D. (ed.), Children's Intellectual Rights, New Directions for Child Development, No. 33, Jossey-Bass, San Francisco, pp. 7-23.

Ward, S. L, and Overton, W. F. (1990). Semantic familiarity, relevance, and the development of deductive reasoning. Dev. Psychol. 26: 488-493.

Wason, P. C., and Johnson-Laird, P. N. (1972). Psychology of Reasoning: Structure and Content, Harvard University Press, Cambridge, MA.

Wassermann, S. (1989). Reflections on measuring thinking, while listening to Mozart's Jupiter symphony. Phi Delta Kappan 70: 365-370.

Weinstein, M. (1988). Reason and critical thinking. Informal Logic 10: 1-20.

West Virginia State Board of Education v. Barnette (1943). 319 U.S. 624. 